\title{
The Nature of the Cell Membrane.
}

IS there a semi-permeable membrane to the cell ? This question is examined by Prof. L. Lapicque in a review of very general interest which accompanies seven more technical contributions in animal, vegetable, or general physiology, in the first number of a new French journal, Annales de Physiologie et de Physicochimie biologique (Paris: Gaston Doin; annual subscription 45 francs outside France). The following, save for reference to some recent cognate American work, is based entirely upon Prof. Lapicque's stimulating and timely article.

Lapicque admits at the outset that he finds the conception of a semi-permeable membrane around the cell a hindrance rather than a help in the interpretation of the behaviour of the cell; he therefore critically examines the case for such a membrane as presented by Bayliss in his great text-book. The idea of a membrane arises naturally when it is realised that protoplasm, though behaving in many ways as a protein sol, can frequently exist in contact with water without dispersing in colloidal solution throughout the aqueous medium. Clearly there is then a protoplasm water interface, and probably every one would agree that protoplasm at this interface has different properties from those characteristic of the main mass of protoplasm. Do these properties, however, necessarily include a different penetrability to solutes which justifies its distinction as a semipermeable membrane enveloping a mass of readily permeable plasm? Even the advocates of the membrane will probably agree it is a phenomenon of the surface and that particles of protoplasm may lose and regain these surface characteristics as they leave or enter the surface layer. Certainly the ease with which the protoplasmic surface changes in amœboid movement, leaving no collapsed membrane as the surface retracts, suggests that any change undergone as protoplasm enters the surface layer is reversible in nature. Whenever a permanent structural membrane can be identified at the surface of the cell, it is something distinct from the surface of the protoplasm, as is the cellulose wall of the plant, and is not the seat of any semi-permeable properties shown by the protoplast, so that in plasmolysis the plant protoplast withdraws itself inward from the permeable cellulose wall around it. The semipermeable properties of the hypothetical membrane are usually interpreted as due to a sieve-like action. From this view-point no non-living semi-permeable membrane has been shown experimentally to be impermeable to molecules of less than about twenty atoms. The living membrane, however, is assumed to control the passage of inorganic ions. One may invoke the view that such ions move accompanied by a cluster of water molecules, but the fact remains that the nonliving membranes fail to arrest their passage.

The distribution of ions upon either side of a semipermeable membrane is now frequently attributed to the Donnan equilibrium, when a non-diffusible colloid on one side of the membrane forms ionisable salts with electrolytes. Consideration of the case of gelatin, however, shows that so long as the colloid is non-diffusible, no special membrane is required for the existence of a Donnan equilibrium.

Thus whilst for mathematical and physico-chemical argument the ideal semi-permeable membrane is a necessary concept, in experimental fact it has never been demonstrated, and there are considerable difficulties in assuming its existence. For example, botanists realise that inorganic salts must diffuse freely into the plant, and they interpret experimental observations of recovery from plasmolysis induced by external concentrations of inorganic salts as evidence that such diffusion is occurring. On the other hand, present data as to the entry of salts, as summarised recently by Stiles in his monograph upon permeability, do not support the assumption that salts will diffuse through the plant protoplast until the ratio of salt concentrations in external solution and in the vacuole will be unity.

Bayliss argued that the resistance of the cell to the electric current, in view of its content in free electrolytes, could only be explained on the assumption of semi-permeability. Lapicque points out that if this was the true explanation, the cell would behave as a condenser in an electric field, and that once the cell was fully polarised no more current would pass. Actually the high resistance may be explained equally well if protoplasm is regarded as a permeable but highly viscous medium.

Bayliss also stipulated the existence of a membrane on the following grounds: (I) In the presence of various electrolytes in solution the cell undergoes a permanent change in volume; (2) the electrolytes within and without the cell differ in kind and in concentration. Lapicque deals with these arguments at some length. The change of volume of the vacuolated cell is admitted, but so also is the fact of recovery from plasmolysis, which shows that we are dealing with slow penetration of salts, not semi-permeability.

In any case this phenomenon is exhibited by the whole thickness of the cytoplasm; there is no. evidence of the special rôle of a surface membrane. In the normal non-vacuolated animal cell, contraction of volume also takes place in the presence of salt solution, but this phenomenon cannot be attributed to the osmotic withdrawal of water from a non-existent vacuole, and is paralleled by the behaviour of gelatin and many other colloids, without superficial semipermeable membranes, when placed in similar salt solutions.

As to the difference in kind and in degree of the concentration of salts within and without a membrane, all through the life of a human being the red blood corpuscles circulate in a medium rich in sodium and poor in potassium, and yet themselves remain rich in potassium and poor in sodium. To maintain this relative difference in concentration a membrane would surely need to be impermeable, but, as Moore and Roaf said in I908, if such a membrane thus imprisons the salts and prevents adjustments of concentration, how did the salts enter the prison?

Lapicque approves the general conclusion of Moore and Roaf that the ratio of concentrations of these ions within and without the living corpuscle depends upon a mobile equilibrium between cell constituents and surrounding liquid, and is not controlled by diffusion restricted by a semi-permeable membrane. Hamburger's experiments have shown these corpuscles to be very permeable to salts, so that any change in the medium produces an exchange of inorganic solutes between the corpuscles and the medium. Hamburger continues to regard the corpuscles as surrounded by a semi-permeable membrane, so that the loss of hæmoglobin in solutions hypotonic beyond a certain degree is explained as due to the bursting of the membrane. Lapicque points out that these laked corpuscles still change in volume with change in salt concentration, just like the original red corpuscles, so that if the membrane is destroyed, some of the properties still remain which it was postulated to explain.

Hoagland and other American workers have recently provided in plant physiology equally puzzling data as to the distribution of inorganic ions within and

NO. 2908, VOL. I I 6] 
without the vacuolated cell. Using Valonia and Nitella, marine and fresh-water algæ forms respectively, which have large enough cells to enable the sap to be collected from individual cells, they supply grounds for thinking that certain inorganic ions, for example potassium, are mainly, if not entirely, in solution in the sap of the vacuole, and yet retain a concentration much higher than that in the outside solution. The case of chlorides is particularly remarkable. Nitella will absorb practically every trace of chloride from the external solution, and will remain alive in distilled water for sixteen days without giving up any detectable trace of chlorine to the water, although containing very appreciable quantities in the vacuole. Hoagland concludes that Nitella under normal conditions possesses uni-directional permeability with reference to chlorine and potassium (Journ. Gen. Physiology, 5, pp. 629-646, I923).

Lapicque concludes that the simple doctrine of the semi-permeable membrane, as employed to explain the salt content and swelling properties of the living cell, will soon appear as inadequate as the astrological conception of the firmament which makes it a crystal vault studded with stars. He adumbrates as factors, in a more adequate explanation, the distribution of salts according to the Donnan equilibrium between a non-diffusible amphoteric colloid and an aqueous membrane, with the great sensitiveness of such an equilibrium to hydrogen ion concentration, and also the hydrophilic behaviour of lipoids, which varies with the proportion of cholesterin to fatty acids or to lecithin. In view also of the modification reported in mitochondria with changes in external medium, he suggests that account may have to be taken of the physiological rôle of these structures, at present almost exclusively studied by the cytologist. Finally, he points out that the protoplasm is the seat of continuous transformation of energy, and that the phenomena under consideration will not admit of solution in terms of a passive semi-permeable membrane. To this last point the supporters of the membrane may reply that they have always assumed that a living cell owes its semi-permeable properties to a living membrane.

\section{Maori Ethnography. ${ }^{1}$}

FOR more than half a century the New Zealand Institute has published in its Transactions a vast amount of valuable information upon all aspects of the history of a group of the most interesting islands in the world. In the earlier years of the Dominion few of the colonists were intimately acquainted with the native language, and fewer still could penetrate the veil that hides the thoughts and ideas of the Maori mind. Many of these ethnological contributions, therefore, are of doubtful reliability. They are, nevertheless, often quoted by anthropological writers in other countries who are unable to discriminate between the wheat and the chaff. After the New Zealand University, with its highly cultivated staffs in its various colleges, began to liberate on the colony graduates trained to careful observation and exposition, it was soon recognised that the scientific study of the native race was an undertaking of the utmost urgency, for the day was already far spent for the garnering of what remained of their rapidly vanishing traditions and beliefs.

New journals were therefore necessary for recording exclusively these anthropological data. The chief of these are the Journal of the Polynesian Society, the Bulletins of the Dominion Museum, and the Records of the Canterbury and Dunedin Museums. It is the tenth volume of the Dominion Museum Bulletins, by Mr. Elsdon Best, that now comes under notice. The author emphasises the qualifications with which any investigator of primitive peoples should be endowed. "No traveller," he says, " or he of short sojourns may delve into . . the inner strata of the mentality of barbaric man. . . ." [The Maori] "ever closely shields his true religion" " [and] ". . . his inner mentality from the inquisitive gaze and analytical probing of inquiring outsiders. . . . In order to open the pages of the inner life . . . of such folks it is highly necessary to gain his confidence. A long residence in their midst, a good knowledge of their language. A quiet and non-critical bearing; a heartfelt sympathy with the feelings and prejudices of the people."

Just such are the qualifications possessed by the author, and consequently he has attained to the position of one of the most trustworthy interpreters of Maori psychology, and one of the highest authorities on their customs and beliefs.

1 Maori Religion: Being an account of the Cosmogony, Anthropogeny, Religious Beliefs and Rites, Magic, and Folk-lore of the Maori Folk of New Zealand. Bulletin No. ro, Section r. By Elsdon Best. (Dominion Museum, Wellington, N.Z., I924.)
The section of the Bulletin we have before us, a closely printed report of 264 pages, incorporates a vast amount of new and valuable, but not easily compressible, matter. It is impossible to do more than summarise its parts (as Mr. Best superscribes his chapters). An introductory part deals with the definition, origin, and development of religion preliminary to a comparison with Maori religion; the second surveys Maori religion and mythology from the evidence of early writers. On this follows a lengthy account of Maori cosmogony, theogeny, and anthropogeny, and further, by a classification of their gods, correcting the mistakes of several ethnologists who have misunderstood the term god as applied to the Maori religion. The New Zealand natives, above all the Polynesians of the Pacific, recognise a supreme divinity-Io-possessing divine attributes more nearly akin to the European idea of godhead. Part five deals with the offerings, human sacrifices, and images by which their spiritual beings can be influenced. This is succeeded by 28 specially interesting pages on the functions of the priests, the sacred places, and divination. Many ethnologists will read with surprise the singular fact that the village latrine was a tuaha or sacred place. Tuaha is the word "applied to any place where men's hair is cut, where tapu food is cast away or offered to supernatural beings," ... and where "rites connected with many matters were conducted." The final part is concerned with an explanation of Maori ritual performances and formulæ-karakia - " a survey of native mentality and its effects as seen in the performance of rites connected with religion and magic," the numerous particulars of which " would require a chapter of cumbrous length " Mr. Best tells us, and so in the present Bulletin he can supply only a few illustrations. His work "The Maori," just about to be published, will, we hope, supply anthropologists with fuller details.

One suggestion may perhaps be permitted, that the numerous ritual formulæ quoted in the native language throughout the book and in several pages of addenda, might, if impossible of verbatim translation, be paraphrased to afford the reader, unacquainted with Maori speech, a general idea of their meaning. This monograph is of exceptional importance. So doubtless will be the second section, which will include a description of Maori magic and many illustrations of native myths and folk-tales. 